
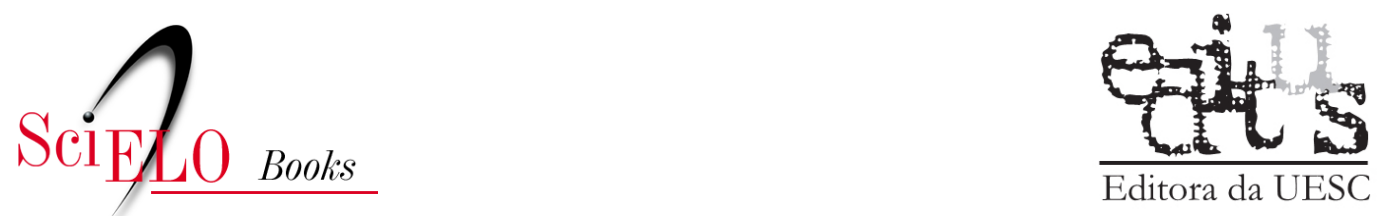

\title{
Múltiplos olhares sobre a velhice representações sociais a partir da percepção de crianças, adultos e idosos
}

\author{
Rita de Cássia da Silva Oliveira \\ Paola Andressa Scortegagna \\ Flávia Oliveira Alves da Silva
}

\section{SciELO Books / SciELO Livros / SciELO Libros}

OLIVEIRA, R. C. S., SCORTEGAGNA, P. A., and SILVA, F. O. A. Múltiplos olhares sobre a velhice: representações sociais a partir da percepção de crianças, adultos e idosos. In: D'ALENCAR, R. S., ed. A representação social na construção da velhice [online]. Ilhéus, BA: EDITUS. 2017, pp. 189-213. ISBN: 978-85-7455-486-0. https://doi.org/10.7476/9788574554860.0010.

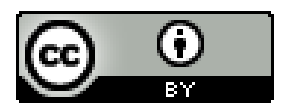

All the contents of this work, except where otherwise noted, is licensed under a Creative Commons Attribution 4.0 International license.

Todo o conteúdo deste trabalho, exceto quando houver ressalva, é publicado sob a licença Creative Commons Atribição 4.0.

Todo el contenido de esta obra, excepto donde se indique lo contrario, está bajo licencia de la licencia Creative Commons Reconocimento 4.0. 


\section{MÚLTIPLOS OLHARES SOBRE A VELHICE: REPRESENTAÇÕES SOCIAIS A PARTIR DA PERCEPÇÃO DE CRIANÇAS, ADULTOS E IDOSOS}

Rita de Cássia da Silva Oliveira

Paola Andressa Scortegagna

Flávia Oliveira Alves da Silva

\section{Palavras iniciais}

Neste século que iniciou há quase duas décadas, a velhice aparece como um desafio que cada vez mais deixa de ser ilusório para tornar-se real.

O tema terceira idade tem estimulado muitas pesquisas e despontado como um dos assuntos em pauta nas discussões sobre as questões da sociedade brasileira.

A velhice enquanto questão social instiga reflexões. A convergência é quase unânime sobre a relevância da temática e a necessidade de políticas públicas e decisões práticas que vão ao encontro desta demanda populacional.

Diante do crescimento demográfico acentuado, a ve1hice passa a ser alvo de estudos e preocupações, na tentativa de redimensionamento dos direitos e deveres dos idosos, possibilitando uma vida digna e de boa qualidade, preconizando o envelhecimento ativo. 
O envelhecimento é inerente à existência de todos os seres vivos. Trata-se de um processo em que o tempo é implacável, deixando suas marcas impressas na personalidade e na face de todos os seres. Entretanto, dentre todas as espécies, apenas a humana tem a repulsa pelo envelhecer, pois se utiliza dos mais variados subterfúgios para criar um disfarce frente à velhice, estabelecendo culturalmente a repulsa à idade.

Todos querem viver muito, mas não desejam envelhecer pelas condições que a sociedade capitalista impõe a esta faixa etária, valorizando o novo e o belo e menosprezando todo aquele que está fora dos padrões sociais e culturais.

Infelizmente historicamente existe uma tendência em definir negativamente a velhice, atribuindo inúmeros preconceitos, mitos e estigmas, os quais em decorrência limitam o espaço de participação, inserção social e empoderamento desta faixa etária.

Diante deste contexto, este texto objetiva refletir sobre diferentes representações sociais da velhice, sob o olhar de crianças, adultos e idosos.

Foi realizada uma pesquisa qualitativa, de campo com, a aplicação de questionários para 10 crianças do quinto ano, 10 adultos e 10 idosos.

\section{Reflexões sobre a velhice: início de diálogo}

Conforme afirma Oliveira (1999, p. 123) “o envelhecimento da população é um fenômeno global que traz importantes repercussões nos campos social e econômico, especialmente nos países em desenvolvimento".

O Brasil registra em sua demografia o envelhecimento da população em ritmo acelerado. Segundo o IBGE (2013), o Brasil possui cerca de 26 milhões de idosos, representando $13 \%$ da população, considerando idoso, as pessoas 
com 60 anos ou mais segundo a legislação específica, o Estatuto do Idoso, Lei 10.741/2003.

Com esta mudança na pirâmide etária, com o aumento quantitativo do contingente de idosos, somado a ampliação da longevidade, outros aspectos se evidenciam e contribuem diretamente para este novo desenho demográfico, entre os quais o declinio da taxa de fertilidade e mortalidade.

Embora o fenômeno do aumento da população idosa em nivel mundial tenha sido anunciado e de certa maneira até previsto em estatísticas, ainda não constitui como prioridade para orientar as políticas e nortear os planos de governo.

Como decorrência, novas demandas sociais se apresentam nos campos da saúde, transporte, habitação, segurança, previdência social e educação, que constituem desafios para a sociedade, sendo necessário um redimensionamento de politicas públicas e ações práticas para atender este segmento etário e resgatar a dívida social historicamente acumulada.

Nesse âmbito, "os velhos precisam de um espaço de fala que torne possivel uma ressignificação de seu eu. Algo que lhes permita relançar o desejo e manter o olhar sobre si” (CASTRO, 2001, p. 68).

Entender que o envelhecimento é natural constitui um fator importante para a aceitação da própria velhice e dos idosos na sociedade. Este pensamento permite não só a própria aceitação, mas uma subjetividade de respeito e valorização desta faixa etária, para si mesmo e extensiva aos demais que atingem esta idade.

Considerando a ideia de Lima, Silva e Galhardoni (2008, p. 795),

o processo de envelhecimento e a velhice são considerados duas esferas complementares e indissociáveis. Vale dizer, consideramos o envelhecimento como um processo que, no plano individual, implica múltiplas trajetórias de vida e, no plano 
coletivo, se constrói sob diferentes influências de ordem sociocultural, tais como: acesso a oportunidades educacionais, adoção de cuidados em saúde, e realização de ações que acompanham o curso da vida, e se estendem às fases tardias da vida, como a velhice. Nesse sentido, enquanto envelhecimento se define como processo sociovital multifacetado ao longo de todo o curso da vida, a velhice denota o estado de "ser velho", condição que resulta do processo de envelhecimento que gerações vivenciaram e vivenciam dentro de contextos sociais, politicos e individuais diversos.

A velhice é um processo complexo que envolve uma multiplicidade de fatores e dimensões: biológica, social, psicológica, econômica, cultural e ideológica que interferem diretamente na vida do idoso.

Assim, pode-se ressaltar que

o ser humano, em sua complexidade, não se reduz ao aspecto físico, mas incorpora a influência da sociedade em que vive, aspectos culturais e psicológicos que, inter-relacionados, constituem o "todo do ser humano" e contribuem cada qual com parcelas importantes no processo de envelhecimento. (OLIVEIRA, 1999, p. 61).

A velhice, enquanto etapa da vida, é socialmente construída e consolidada variando de cultura para cultura. Assim, "a velhice é um tempo de sintese de todas as épocas anteriores do ciclo de vida" (SALGADO, 1991, p.08).

Moragas (1991, p. 54) destaca que "muita gente se surpreende ao comprovar que pessoas idosas desempenham atividades físicas e intelectuais com plena efetividade”. $\mathrm{Na}$ sociedade brasileira, na maioria das vezes, convive-se com um conceito pejorativo da velhice, acrescido do descaso geral com relação a essa faixa etária. Há a desconsideração da capacidade de produção e de aprendizagem para o idoso. Assim, Albom (1998, p. 117) considera que 
[...] à medida que se cresce, aprende-se mais. Se ficássemos parados nos vinte e dois anos, ficaríamos sempre ignorantes como quando tínhamos vinte e dois anos. Envelhecer não é só decair fisicamente. É crescer. É mais do que o fato negativo de que se vai morrer, é também o fato positivo de que se compreende que se vai morrer e que se pode viver melhor por causa disso.

Existe atualmente uma tendência em desvalorizar o idoso, tratá-lo de maneira preconceituosa, reforçando um estereótipo negativo da velhice, ressaltando a incapacidade, improdutividade, doenças, solidão e marginalização social, desconsiderando assim a capacidade que ele possui de realizar suas atividades, seus desejos e expectativas, rejeitando a subjetividade de cada um.

A aplicabilidade da palavra "velho" reveste-se de conotações pejorativas e negativas. A sociedade valoriza e cultua a juventude, enaltecendo o novo, o belo em detrimento da velhice, estabelecendo um universo de rejeição e exclusão social.

Muitos são os mitos e preconceitos socialmente construídos para a velhice, entretanto não são cientificamente comprovados. O Brasil precisa equacionar a situação do idoso e suas reais necessidades para enfrentá-las e possibilitar melhor qualidade de vida e empoderamento.

\section{Representações sociais da velhice: a consoli- dação do coletivo}

As representações sociais da velhice apresentam a maneira de interpretar e pensar a realidade, refletem a maneira como a sociedade entende esta etapa da vida, a forma de conhecimento dos indivíduos que fixam suas posições referentes a diferentes situações que envolvem esta faixa etária. A representação social é um conhecimento prático, que dá 
sentido coletivo a um determinado fato, situação ou acontecimento, aqui considerada uma etapa da vida, a velhice.

Decorrentes do processo de socialização, as representações sociais estão associadas diretamente ao coletivo social.

Pode-se afirmar também que a representação retrata a posição que as pessoas ocupam na sociedade, ou seja, toda representação social é a representação de alguma coisa ou de alguém, possibilitando a aceitação ou não, uma visão positiva ou negativa pela qual se estabelece a relação com o mundo e os acontecimentos.

Logo, velhice e idoso são objetos socialmente relevantes, passiveis de representações sociais. Cada indivíduo vive num mundo e sofre influências sociais, reforçando e reproduzindo em suas atitudes ideias pré-concebidas e comportamentos que fazemos deles.

A velhice é considerada uma categoria social, "constitui um termo que quase sempre nos causa calafrios, uma palavra carregada de inquietude, de fraqueza e por vezes de angústia" (MINOIS, 1999, p.11).

Conforme expressa Jodelet (2001), as representações sociais são modalidades de conhecimentos práticos orientados para a compreensão do contexto social em que se vive. As formas de conhecimento são socialmente elaboradas e compartilhadas, contribuindo para a construção de uma realidade comum, que permite a comunicação entre os indivíduos.

Segundo o dicionário Aurélio (FERREIRA, 1975. p. 564), a representação é "o conteúdo concreto apreendido pelos sentidos, pela imaginação, pela memória ou pelo pensamento" é a "reprodução daquilo que se pensa" sendo manifestada em atitudes, gestos e comportamentos.

Por intermédio do aporte teórico da representação social, torna-se possivel penetrar no cotidiano dos indivíduos, considerando seus valores e identidades culturais, buscando suas verdadeiras raí- 
zes e origens, proporcionando o descobrimento de aspectos antigos e novos de sua identidade (ALEXANDRE, 2004, p. 130).

Pode-se considerar que as representações do mundo social são sempre determinadas pelos interesses dos grupos que as forjam.

A origem do conceito de representação social vem do termo "representação coletiva" desenvolvido por Durkheim, que considera o pensamento originário da sociedade e só pode ser encontrado na experiência social. A representação coletiva, transmitida como herança dos antepassados, não se reduz à soma das representações dos indivíduos que compõem a sociedade, mas é mais do que isto, significa uma superação, possibilitando a formação do coletivo.

Moscovici (2004) acrescenta à transmissão da herança coletiva, a interferência do indivíduo que, pelo papel ativo que desempenha, acrescenta novos elementos na construção de uma sociedade e da representação social de diferentes acontecimentos.

"As representações sociais são fenômenos sociais que têm de ser entendidos a partir do seu contexto de produção, isto é, a partir das funções simbólicas e ideológicas a que servem e das formas de comunicação onde circulam" (ALEXANDRE, 2004, p. 131).

Atualmente existem formas diferentes de envelhecer e também diferentes formas de encarar a velhice. Na sociedade brasileira, historicamente, a visão de velhice sempre esteve impregnada de sentimentos negativos, associados ao desgaste, às perdas e à marginalização. Contraditoriamente, surge um novo paradigma que se amplia, o qual questiona esta visão pejorativa, sobrepondo diferentes oportunidades, experiências positivas, valorizando o envelhecimento bem sucedido, saudável e ativo.

Os conhecimentos e a realidade, conforme afirma Alexandre (2004, p. 132), "deverão ser compreendidos dentro de contextos sociais específicos e suas relações analisadas 
a partir destes contextos." Assim, as representações sociais também orientam a conduta dos indivíduos, modelando o comportamento, é uma preparação para a ação, porém com a dimensão social somada à individual, possibilita também a manutenção, modificação ou reconstrução da conduta.

"A formação das representações sociais a partir da realidade da vida cotidiana constitui uma grande força para que estas possam ser tratadas e reconhecidas como conhecimento pela sociedade." (ALEXANDRE, 2004, p. 134). A representação social é uma modalidade de conhecimento e uma interpretação do real, determinada pela estrutura da sociedade onde ela se desenvolve.

Desta maneira, os mitos são construídos e a representação social da velhice se consolida na sociedade brasileira, reforçando a negatividade e a não cientificidade. A manifestação individual e a postura com relação à velhice dependem da interiorização de uma realidade já construída.

Só a partir do momento em que ele se apropria das formas de pensamento e dos modelos de conduta de sua cultura é que tais representações vão se consolidando subjetivamente, podendo assim, intervir na sua interpretação do mundo e de si mesmo, isto é, na construção de sua identidade pessoal. (SANTOS, 1994, p. 133).

Ressalta-se a originalidade de cada individuo nesse trajeto ao assumir o mundo dos outros (apropriar-se desse mundo); na medida em que o indivíduo assume esta realidade e se torna membro da sociedade, ele compartilha este universo simbólico, implica um processo de assimilação e transformação dos conhecimentos e símbolos transmitidos.

O processo de envelhecimento adquire singularidades, revestido de subjetivismos porque existem diferentes formas de envelhecer e de encarar a velhice. Entretanto, com certa frequência depara-se na história com muitos 
mitos imputados à velhice, associando-a ao desgaste, às perdas, às doenças.

Entre os mitos consolidados socialmente referentes à velhice, podem ser citados: incapacidade de aprender, incapacidade sexual, improdutividade.

Porém, este aspecto negativo tem sido questionado pela própria ampliação da longevidade, do envelhecimento ativo e pela busca de maior inserção, integração e participação social do idoso.

\section{Mitos referentes à velhice: uma realidade incômoda}

A representação social da velhice é uma construção social que interfere sobre a maneira como se encara a velhice dos outros e a própria velhice, além de também nortear as ações e práticas referentes a esta faixa etária. Esta conceituação negativa induzida pela consciência coletiva na sociedade capitalista impulsiona a ideia de envelhecimento e a velhice como fim da vida ativa.

Negar os estigmas e preconceitos atribuídos aos idosos é tão cruel quanto infantilizar ou tratar o idoso de maneira assistencialista. O passo mais importante é o reconhecimento para que os idosos tenham seu valor e papel acolhidos e respeitados dentro da sociedade.

É difícil determinar o que é velho, em todas as delimitações, uma vez que a velhice é um processo. Portanto, ela não se dá de repente, é algo gradativo.

A velhice, conforme Farias (1990), é um período de muitas mudanças para o indivíduo. A sociedade ainda não definiu papéis para essa parcela da população, com graves problemas e prejuízos de diferentes dimensões, em especial de ordem econômica.

"O indivíduo deve se preparar para a velhice, para que tenha uma boa vida social e afetiva e continue dando 
sua contribuição para a humanidade" (OLIVEIRA, 1998, p. 47). Toda a experiência de vida supõe uma dimensão adversa que não se pode negar ou ignorar, mas supõe, ao mesmo tempo, uma dimensão positiva não menos real. São duas dimensões contraditórias de uma mesma vivência: uma situação de crescimento ou de decadência (OLIVEIRA, 1998).

A afetividade positiva em relação aos idosos representa uma grande possibilidade de encarar a velhice com naturalidade e tranquilidade, alcançando uma convivência mais harmoniosa com os idosos e consigo mesmo.

Segundo Oliveira (1998, p. 73),

o impasse e a tragicidade da velhice perpetua na ausência da atribuição de qualquer lugar social e reconhecimento simbólico, os percursos da temporalização se silenciam e se impossibilita qualquer manifestação de subjetividade. Talvez seja mais fácil, através de gerações, negar os estigmas e preconceitos atribuídos aos idosos, pois à medida que são reconhecidos, deve-se reagir e mudá-los. Será o passo mais importante para que os idosos tenham seu valor e papel acolhidos e respeitados dentro da sociedade.

Mira y Lopez (1981) fazem uma análise e atribuem três preconceitos referentes à velhice na sociedade. A sociedade aplica a lei do "tudo ou nada" para a velhice,

as leis são criadas para o homem de meio termo e em favor deles são legislados. Esses critérios racionais deixam de ser válidos no momento em que o indivíduo transpõe a fronteira da velhice, quando a sociedade o condena à inatividade, improdutividade e dependência (MIRA y LOPEZ, 1981, p. 28).

Um segundo preconceito é a forma desigual com que a sociedade enquadra o velho e o jovem com relação ao aspecto econômico. É nítida a predileção pelo jovem sob 
a alegação de que a velhice acarreta perdas no aspecto físico e mental e, em decorrência, prejuízos para a produtividade. Não se pode negar a existência de diferenças nos desempenhos entre as faixas etárias variadas, entre as quais se pode registrar o ritmo empreendido em algumas funções, mas que pode ser compensado por outros aspectos como a experiência dos idosos.

Como um terceiro preconceito, Mira y Lopez apontam a incapacidade do idoso para a aprendizagem. O ritmo pode sofrer alteração, mas tanto aprender coisas novas como se adaptar às exigências e novas condições de vida são possíveis ao idoso. A capacidade de aprendizagem não é afetada pela idade, mas é facilitada pela associação com experiências anteriores.

Muitos são os fatores que influenciam no desempenho do idoso na aprendizagem, entre os quais a origem, o nivel de instrução e a profissão.

Atualmente a mídia cultua a juventude e relaciona a felicidade a este tempo da vida, entretanto, a felicidade e a beleza são compativeis com qualquer fase da vida do indivíduo, basta aceitar a si e a própria velhice, ampliando este sentimento positivo e otimista aos demais idosos. Não se pode viver tendo como parâmetro a própria juventude, porque certamente irá viver de passado e ilusões, gerando limitações e frustrações.

A velhice é uma etapa da vida que enfrenta uma crise com diferentes dimensões: crise da afetividade, porque seus vínculos afetivos se enfraquecem com o distanciamento dos filhos que irão constituir suas próprias famílias e, muitas vezes, perde também o cônjuge que o acompanhou por muitas décadas; outra é a crise da ociosidade, porque a pessoa perdeu seu vínculo formal com o mercado de trabalho, assumindo a categoria de aposentado, o que na sociedade capitalista é interpretado de maneira equivocada como improdutivo e incapaz, necessitando de um redimensionamento de suas atividades laborais; crise 
cultural, porque sofre os impactos negativos atribuídos à velhice, sentindo-se desvalorizado, marginalizado e alvo de preconceitos.

$\mathrm{Na}$ sociedade industrial, na qual a essência repousa na produção, o espaço para os idosos é cada vez mais reduzido pela exclusão compulsória desse segmento do circuito de produção.

Considerando o aumento da longevidade, os efeitos da aposentadoria compulsória são muito grandes, provocando dificuldades de diversas ordens. Nesse sentido, a ideia da necessidade de preparação e orientação para a aposentadoria é convergente, resultando em uma transição mais suave e menos traumática.

Segundo Gaiarsa (1989), ser velho, além de um fato, é um conjunto de convenções sociais da pior espécie. Não se sabe o que pesa mais sobre os velhos, se a idade ou a ideia que fazem de si mesmos, movidos pelo modo como são tratados, levados pelas ideias tantas vezes vingativas que orientam o comportamento da maioria frente a eles. $\mathrm{O}$ idoso que foi afastado do convivio dos colegas de profissão e do próprio trabalho, amplia o tempo vazio e o sentimento de inutilidade, principalmente somadas às dificuldades financeiras e perdas afetivas. O idoso é vulnerável à solidão, à inutilidade e às carências afetivas e financeiras. Não existe fundamento científico para comprovar a inutilidade profissional dos idosos e os aspectos negativos que a eles se atribuem: ou são mitos, ou então, evidências insignificantes.

A velhice é condicionada socialmente, e a marginalização social do idoso é um problema cultural. A velhice é, antes de tudo, um problema social, ou uma situação política, e uma concepção social, e só em segundo lugar representa uma modificação funcional e orgânica (MOSQUERA, 1978).

Mardegan (1993) propõe para a crise vivencial da velhice uma solução, qual seja, o idoso deve continuar perseguindo seus objetivos que dão significado a sua própria vida 
ou reestruturar e (res) significar estes objetivos, considerando a vida como um processo contínuo de redefinições e redescobertas, ancorada na ideia de um eterno crescimento. A velhice é uma das etapas cronologicamente considerada como a que se conserva por mais tempo ao longo da vida porque é um destino viver por muito tempo e o ideal é viver com qualidade e de maneira saudável. "A arte de viver está juntamente na renovação constante dos objetivos e expectativas de vida" (MARDEGAN, 1993, p. 73).

A incapacidade sexual também reforça a lista de preconceitos com relação ao idoso e se caracteriza como mais um dos mitos que acompanha a velhice, uma vez que robustez fisica e vida regrada permitem ao idoso usufruir de sua capacidade sexual até idade bem avançada (STEGLI$\mathrm{CH}, 1992)$.

Com o passar dos anos, há uma modificação da sexualidade que não significa necessariamente declínio, nem muito menos deterioração. O corpo funciona em outro ritmo e com outras possibilidades. A troca de carinho se incrementa na medida em que diminui a preocupação com a exigência de um grande desempenho sexual.

Não se pode deixar de considerar que, após os 60 anos, os parâmetros de beleza, de sedução e de atração não dependem tanto da estética convencional do corpo jovem, mas da química da atração entre os seres humanos que ainda se constitui em um dos grandes mistérios da espécie.

O envelhecimento não implica necessariamente deterioração física e mental, porque varia quanto ao estilo de vida de cada pessoa e da representação que cada um atribui à velhice, sendo importante a criação de um modelo positivo, de envelhecimento ativo, saudável e com qualidade de vida.

A representação social é tudo o que pode ser expresso representado, vista numa perspectiva estrutural, interligada entre as representações e 
a realidade; é também produtora de novas práticas, por meio da exteriorização dos pensamentos, da imaginação. Neste ponto, inspirada em Moscovici, as representações sociais são entendidas como passarelas entre o indivíduo e a sociedade, pois ambos estão efetuando influências (SILVA, 2009, p. 57).

Em um estudo, Moody (1989) estabelece quatro modelos de percepções que podem ser consideradas como estágios de evolução da representação da velhice na sociedade.

O primeiro estágio, o de repulsão, o mais cruel porque se refere às atitudes negativas praticadas sobre o envelhecimento. O idoso é considerado improdutivo e excluído do sistema de produção. Nesta concepção de inutilidade que recai sobre esta faixa etária, o idoso também é discriminado, isolado socialmente, são atribuídos a esta etapa da vida inúmeros preconceitos infundados cientificamente, ou seja, é atribuído um quadro desalentador e de incapacidade generalizada, inclusive cognitiva.

O segundo estágio refere-se à percepção relacionada aos serviços sociais, atribuindo ao entretenimento, na perspectiva de o idoso ser consumidor, uma maneira de mantê-lo ocupado pelas atividades e entretido em seu tempo de lazer.

Evidencia-se que a sociedade capitalista voltada para o consumo busca integrar os ambientes às necessidades e interesses dos idosos, como consumidores, enaltecendo o idoso de uma classe social economicamente mais privilegiada.

A participação é o elemento de referência do terceiro estágio, no qual os idosos voltam-se para assumirem novos papéis sociais, (res) significando e redimensionando sua realidade, na tentativa de superar os estereótipos negativos pré-estabelecidos para a velhice, desacreditando esta faixa etária no que se refere à participação e à inserção social. 
A atividade criteriosamente selecionada se converte em condição fundamental para uma vida com êxito.

Neste estágio, a educação é determinante na busca pela aquisição de conhecimentos, atualização que viabiliza uma maior inserção social do idoso, procurando transpor as limitações e os preconceitos que, aprioristicamente, são impostos a essa faixa etária.

Esse terceiro modelo reforça a participação e integração do idoso na sociedade repudiando a segregação e o isolamento da população idosa.

Por último, o quarto estágio é considerado o ideal, qual seja, o da autorrealização. O idoso busca a realização de seus projetos de vida que anteriormente não puderam ser concretizados, encara a velhice como um período de realizações, de descobertas de habilidades não desenvolvidas, de criatividade baseada nas experiências adquiridas ao longo da vida. Essa busca pela realização traz uma satisfação pessoal, crescimento e mudanças psicológicas e repercute em maior inserção social pela elevação da autoestima.

As atividades e a participação social são aspectos relevantes que possibilitam a melhoria do perfil funcional dos indivíduos dessa faixa populacional.

Esses modelos, brevemente citados, estão presentes na consciência coletiva e podem avalizar intervenções sociais e formas de superar os modelos pré-estabelecidos sobre a velhice. Nestes modelos flagram-se diferentes concepções da velhice. Considera-se negativo e inadequado o primeiro, e bastante limitado o segundo. O terceiro e o quarto podem se tornar como pontos de referência importantes para estabelecerem diferentes programas e atividades de intervenção.

Considera-se que o quarto estágio é o ideal e com estas ideias é que se devem dimensionar as atividades voltadas para o idoso. 


\section{Diferentes olhares sobre a velhice}

Com o objetivo de refletir sobre as diferentes representações sociais da velhice, sob o olhar das crianças, adultos e de idosos, foi realizada uma pesquisa qualitativa e de campo.

Como instrumento de coleta de dados, foi utilizado um questionário com perguntas abertas, aplicado para 10 crianças do quinto ano e 10 adultos de uma escola municipal da cidade de Ponta Grossa e 10 idosos da Universidade Aberta para a Terceira Idade. Os sujeitos da pesquisa foram escolhidos aleatoriamente, considerando o interesse e a disponibilidade em responder o questionário.

Das 10 crianças que responderam o questionário, 5 são meninas e 5 são meninos, com idade entre 9 e 10 anos. Destas, 9 possuem idosos na família, considerando que a convivência com o idoso e a afetividade com relação a eles podem ser estendidas a outros idosos, repercutindo em uma representação social mais otimista e carinhosa referente a esta faixa etária.

As crianças foram questionadas sobre "O que é idoso?”, e as respostas estão relacionadas no Quadro 1.

QUADRO 1 - O que é idoso? (crianças)

- Pessoas com mais idade.

- Idoso é uma pessoa bastante de idade que precisa de várias ajudas.

- Idoso pra mim é uma pessoa que tem mais de 60 anos.

- É uma pessoa com mais experiência, com mais idade, mais vivida e mais sábia.

- É uma pessoa de muita idade, cabelos brancos e com bastante experiência de vida.

- Uma pessoa mais velha.

- Uma pessoa velha.

- Senhor que é divertido.

- Uma pessoa que já viveu muitos anos.

- Idoso é uma pessoa mais de 65 anos que nós devemos respeitar. O tempo passa, por isso devemos nos preparar porque um dia nós seremos idosos.

Fonte: Elaboração das autoras a partir dos dados dos questionários. 
Os 10 adultos que responderam os questionários possuem a idade entre 22 e 52 anos, sendo dois do sexo masculino e 8 do sexo feminino. Todos apontaram que possuem idosos na família. As respostas relativas sobre “O que é idoso?" estão apresentadas no Quadro 2.

QUADRO 2 - O que é idoso? (adultos)

- Pessoas com mais de 60 anos, uns são ativos dependendo da vida que levaram anteriormente, e outros, se não se cuidaram em relação à saúde, têm limitações.

- São pessoas com idade acima de 60 anos.

- É uma fase da vida, é o avançar dos anos. É estar na fase da vida em que ela passa rápido, porém o corpo reage devagar.

- Idosos são todas as pessoas acima de 60 anos, sendo elas ativas em relação ao trabalho ou não. São pessoas com experiências de vida ímpar.

- É o indivíduo com mais de 60 anos ou que possui idade avançada.

- Idoso é uma pessoa que tem que viver com as limitações impostas pela própria natureza humana, mas acima de tudo usar de toda a sua experiência para viver da melhor maneira possível.

- Uma pessoa que tem idade superior a 65 anos e tem muita experiência de vida.

- Pessoas acima de 60 anos, ativas ou não. Normalmente são pessoas com grande experiência de vida que muito podem nos ensinar, basta apenas terem oportunidade.

- Pessoas com mais de 65 anos.

- É todo e qualquer indivíduo acima de 60 anos, diferente do termo velhice que independe de condições de saúde e hábitos de vida.

Fonte: Elaboração das autoras a partir dos dados dos questionários.

Participaram da pesquisa, 10 idosos da Universidade Aberta para a Terceira Idade, com a idade entre 64 e 85 anos, sendo 3 do sexo masculino e 7 do sexo feminino. Responderam também que 8 possuem convivência com idosos, sendo cônjuge, pai ou mãe.

Referente ao que pensam sobre "O que é idoso?", as respostas estão registradas no Quadro 3. 
QUADRO 3 - O que é idoso? (idosos)

- É uma pessoa com grande experiência de vida. Que passou por muitas coisas boas e más.

- Pessoa com certa idade já avançada que traz consigo uma vasta experiência de vida.

- Uma pessoa que tem experiência de vida. Que tenha mais de 60 anos e tem sua vida ativa, como prática de esporte, dança, etc.

- Segundo a legislação brasileira, idoso é a pessoa com 60 anos ou mais de idade, com experiência de vida e sabedoria.

- Idoso é a pessoa que tem mais de 60 anos e que possui muitas experiências de vida, já enfrentou muitas dificuldades e muitas aprendizagens e pode contribuir com os mais jovens.

- Tem muitos anos de vida, com mais de 60 anos, podem aprender ainda muitas coisas e realizar seus sonhos.

- Tem acima de 60 anos, muitas experiências, passaram por momentos felizes e tristes.

- Uma pessoa que já atingiu uma certa idade, ou seja, acima de 65 anos.

- Idoso que eu entendo e posso dizer com todas as letras: é uma pessoa com muita experiência de vida, nunca deixa a peteca cair e sempre bola para frente. Com muita saúde, garra e vontade de viver cada vez mais.

- Idoso é a pessoa que tem espírito jovem, alegre, participativo, sempre disposto. É aquele que não parou no tempo e no espaço.

Fonte: Elaboração das autoras a partir dos dados dos questionários.

Pode-se perceber que as crianças apresentaram uma visão positiva sobre o idoso, ressaltando a relação com a idade (60 anos), a questão da sabedoria e da experiência aliada a sentimentos como respeito, e registram a preocupação com o futuro quando forem idosos.

As crianças estabelecem a ideia de idoso baseada no fator cronológico, o que vai ao encontro do previsto no Estatuto do Idoso, considerando idoso o indivíduo que possui 60 anos ou mais.

Duas crianças fizeram referência à necessidade que o idoso possui de ajuda, registrando desta maneira a fragilidade que caracteriza esta faixa etária. Registraram 
também as mudanças estéticas como cabelos brancos, entretanto indicaram que o idoso possui sabedoria e experiências vivenciadas ao longo de sua vida.

Nas respostas dos adultos sobre "O que é idoso?", registra-se também o fator cronológico, sendo 60 anos o marco de ingresso nesta faixa etária, embora dois tenham respondido que a velhice se inicia aos 65 anos. A legislação brasileira indica 60 anos como o início da velhice (Estatuto do Idoso), mas alguns benefícios são usufruídos apenas depois dos 65 anos.

Nota-se que existem nestas respostas dos adultos uma conotação menos positiva do que nas das crianças, considerando a existência de limitações físicas impostas pela natureza humana, reflexo da longevidade. Ressaltam também a experiência de vida que o idoso possui e a capacidade de ensinar, variando conforme as oportunidades.

Referente à ideia dos idosos sobre o que é idoso, pode-se considerar que todos referenciaram que é uma pessoa com 60 anos ou mais, com muita experiência de vida, sabedoria e situações variadas ao longo de suas vivências.

Os sujeitos da pesquisa responderam também a questão "O que você fará quando ficar idoso?", e as respostas também apresentaram certa convergência e podese notar que está se estabelecendo uma nova representação social no coletivo das crianças, com o olhar mais otimista sobre a velhice, protagonizando um idoso mais ativo e participativo.

As crianças ressaltaram a ideia de que quando forem idosos, vão viver bem, com a família, passear, cuidar dos netos, aposentar a curtir a vida. Pelas respostas, concluise que, para este grupo, ser idoso não possui conotação negativa, ao contrário, é tempo de viver e de aproveitar junto com as pessoas que ama, em especial os netos. A velhice, por esta faixa etária, é projetada positivamente (Quadro 4). 
QUADRO 4 - O que você fará quando ficar idoso? (crianças)

- Vou sair com meus netos

- Viver com a minha família

- Eu quero ser fazendeira

- Vou ser responsável, vou descansar, vou ajudar a resolver problemas, vou cuidar dos meus netos

- Eu vou descansar, visitar meus parentes, ficar com os meus netos, vou ficar na varanda e vou me aposentar

- Vou ficar mais velho

- Ficar em casa, limpar a casa

- Eu seria legal com as pessoas, iria ajudar eles

- Morar no hotel

- Me aposentar, ter minha casa e curtir minha vida

Fonte: Elaboração das autoras a partir dos dados dos questionários.

Diante das respostas fornecidas pelos adultos, podese perceber que a representação social que possuem da velhice também é positiva. Reservam para esta etapa da vida momentos de convivência com os netos, alegria, descontração, buscando uma vida saudável e com saúde.

Nas considerações apresentadas, registram que esperam viver muito e uma longevidade plena, demonstram a preocupação em se preparar para esta etapa por meio de uma vida ativa, alimentação saudável, praticando esportes e procurando uma boa qualidade de vida (Quadro 5).

QUADRO 5 - O que você fará quando ficar idoso? (adultos)

- Aproveito todas as oportunidades que a vida me oferece, fazer mais amizades, participar do social e procurar fazer atividades físicas e viver a vida.

- Ter uma vida ativa, realizando várias tarefas, exercícios físicos com o objetivo de ficar com a saúde física e intelectual harmonizada.

- Espero poder usufruir desta fase. Estar com a saúde com bons resultados e dispor de tempo para viver o tempo.

- Quero ser um idoso saudável para conseguir continuar vivendo ativamente.

(Continua) 
(Conclusão)

- Ainda não pensei sobre isso! Provavelmente irei trabalhar em algo compatível com meu estado de saúde e condições físicas.

- Morar no litoral paranaense, cuidar da minha alimentação, visando boa qualidade de vida.

- Cuidarei da família e da saúde e buscarei o máximo de qualidade de vida possível, talvez morar no litoral.

- Procurarei ter uma vida muito ativa e saudável. Praticando sempre qualquer atividade física que estiver ao meu alcance.

- Espero ter saúde para poder aproveitar o que resta da vida: culinária, artesanato e esportes.

- Vou procurar manter hábitos alimentares saudáveis, praticar atividades físicas e orientar ao máximo meus descendentes e ter uma vida como minha mãe, não ser sedentário.

Fonte: Elaboração das autoras a partir dos dados dos questionários.

As respostas dos idosos também convergem para uma visão positiva da velhice, na medida em que buscam para esta etapa da vida, além da realização de atividades físicas, intensificar a convivência com os netos e familiares, buscar novas amizades e fortalecer as já existentes. Buscam também novos conhecimentos, o que possibilita maior inserção e participação social.

A visão que predomina é a de desfrutar a vida, não atribuindo preconceitos ou reforçando os estereótipos e mitos negativos que socialmente são estabelecidos e culturalmente consolidados (Quadro 6).

QUADRO 6 - O que você fará quando ficar idoso? (idosos)

- Ter minha vida ativa, pois se me acomodar, morro logo.

- Enquanto eu puder, e que esteja bem de saúde, continuarei trabalhando, praticando atividades físicas, enfim procurando na medida do possível fazer uma boa alimentação, me cuidar. Sempre seguindo a Deus, procurando evoluir com toda a experiência de vida.

(Continua) 
(Conclusão)

- Agradecendo a Deus por estar viva e pedindo saúde, para continuar com meus entes queridos.

- Atividade física, fazer passeios e viagens, aproveitar a companhia dos familiares, cuidar da saúde.

- Quero ser ágil se a saúde me permitir. Quem sabe ensinar e aprender coisas novas.

- Cuidar dos netos, cuidar da minha saúde e do resto da vida que ainda irei ter, viver com mais contato com a natureza e permanecer mais em casa.

- O importante é procurar atividades como praticar esporte, frequentar grupos de trabalho, dedicar-se à leitura, caminhadas enfim procurar levar uma vida o mais saudável possível, viver dentro do que Deus lhe oferece.

- Tento ser feliz e aproveitar o que é melhor da vida até quando Deus quiser.

- Considero-me bastante jovem ativa, fazendo todos os afazeres, estudando, viajando, tricotando, trocando receitas, brincando com as netas e fazendo novas amizades.

- Continuo pedindo a Deus muita saúde na vida para eu continuar na UATI, é o que me faz muito, muito feliz, com vontade de viver cada vez mais.

Fonte: Elaboração das autoras a partir dos dados dos questionários.

\section{Esboçando algumas considerações}

Contraditoriamente à ideia generalizada na sociedade brasileira de que ser idoso é negativo, representa na coletividade a ideia de solidão, isolamento, tristeza, frustração e doença, os três grupos investigados (criança, adulto e idoso) apresentaram a representação social da velhice diferente da culturalmente estabelecida.

Dentre os três grupos percebe-se que apesar da existência de limitações na velhice, os aspectos de positividade são preponderantes, em que se percebe o idoso como um sujeito ativo, que tem capacidade de aprender e de ensinar, possui muitas experiências de vida, o que lhe possibilita desenvolver diferentes ações, estar participando e inserido socialmente.

Estabelecer esta rede de amizades e de conhecimentos atualizados possibilita maiores condições para o en- 
frentamento, de um lado, das questões pessoais, de saúde, perdas afetivas e, de outro, dos aspectos sociais que são impostos pela coletividade, resquícios de uma imagem construída pela sociedade brasileira, reforçando uma cultura voltada para a juventude.

A educação instrumentaliza os idosos com conhecimentos e atualiza nas questões relativas aos direitos fundamentais, às inovações tecnológicas e da sociedade como um todo, mantendo-os informados. Neste aspecto, ressalta-se o papel desenvolvido pelos Programas da Universidade Aberta para a Terceira Idade que influenciam e repercutem na representação social que o idoso possui da velhice e, de certa maneira, contraria o estigma negativo que por muito tempo prevaleceu na sociedade brasileira.

Delineia-se, assim, um novo paradigma da velhice, fundamentado em uma etapa saudável, embora com as limitações advindas da própria natureza, supera os preconceitos de incapacidades existentes, permitindo a realização e participação do idoso em atividades físicas, sociais. Esboça-se um novo idoso, mais ativo, protagonista de sua própria vida e um cidadão pleno. 


\section{Referências}

ALBOM, M. A última grande lição: o sentido da vida. 6. ed. Rio de Janeiro: Sextante, 1998.

ALEXANDRE, Marcos. Representação Social: uma genealogia do conceito. Comum. Rio de Janeiro, v.10, n. 23, p.122138, jul./dez. 2004.

BACELAR, R. Envelhecimento e produtividade: processos de subjetivação. 2. ed. rev. Recife: Fundação Antônio dos Santos Abranches. FASA, 2002.

CASTRO, O. P. Envelhecer: um encontro inesperado? Sapucaí do Sul: Notadez, 2001.

DANIEL, Fernanda; ANTUNES, Anna; AMARAL, Inês. Representações sociais da velhice. Análise Psicológica. Lisboa, v. 32, n. 3, p. 291-301, 2015.

FERREIRA, A. B. H. Novo Dicionário Aurélio da Lingua Portuguesa. Rio de Janeiro: Nova Fronteira, 1975.

GAIARSA, J. A. Como enfrentar a velhice. São Paulo: Ícone, 1989.

INSTITUTO BRASILEIRO DE GEOGRAFIA E ESTATISTICA. Sintese de indicadores sociais - uma análise das condições de vida da população brasileira. Rio de Janeiro, 2013.

JODELET, Denise (Org.) As Representações Sociais. Rio de Janeiro: EDUERJ, 2001.

LIMA, Ângela; SILVA, Henrique; GALHARDONI, Ricardo. Envelhecimento bem-sucedido: trajetórias de um constructo e novas fronteiras. Interface- Comunicação, Saúde, Educação. São Paulo, v. 12, n. 27, p.795-807, 2008.

MARDEGAN JR, E. A idade do Lobo. São Paulo: Mercuryo, 1993. 
MINOIS, Georges. História da Velhice no Ocidente. Portugal, Editora Teorema, 1999.

MIRA y LOPEZ, E. A arte de envelhecer. Rio de Janeiro: Civilização Brasileira, 1981.

MOODY, H. R. Philosophical presuppositions of education for old age. Educational gerontology, Barcelona, CEAC, n. 1, 1989.

MORAGAS, R. M. Gerontología Social: envejecimiento y calidad de vida. Barcelona: Herder, 1991.

MOSCOVICI, Serge. Representações sociais: investigações em Psicologia Social. Petrópolis: Vozes, 2004.

MOSQUERA, Juan. Vida adulta: personalidade e desenvolvimento. Porto Alegre: Sulina, 1978.

OLIVEIRA, Rita de Cássia. Terceira Idade: do repensar dos limites aos sonhos possíveis. São Paulo: Paulinas, 1999.

OLIVEIRA, Rita de Cássia da Silva. Universidade Aberta para a Terceira Idade na Universidade Estadual de Ponta Grossa. 1998. 635f. Tese (Doutorado em Filosofia e Ciências da Educação) - Universidade de Santiago de Compostela, Santiago de Compostela/Espanha, 1998.

SALGADO, M. Velhice, uma nova questão social. São Paulo: Sesc, 1991.

SANTOS, Maria de Fátima de Souza. Representação Social e a relação indivíduo-sociedade. Temas de Psicologia. Ribeirão Preto. v. 2 n. 3, p. 133-142, dez. 1994.

SILVA, Neide de Melo Aguiar. Representações sociais em educação: determinantes teóricos e pesquisas. Blumenau: Edifurb, 2009.

STEGLICH, L. A. Crises normais na vida adulta. Passo Fundo: UPF, 1992. 